\title{
GAME DETEKTIF RESIMEN MAHASISWA BATALYON 209 TEKNOKRAT GAJAH LAMPUNG
}

\author{
Yugisman Palendera $^{1)}$, Yusra Fernando ${ }^{2)}$, Sampurna Dadi Rizkiono ${ }^{3)}$ \\ ${ }^{1,3}$ Jurusan Informatika Fakultas Teknik dan Ilmu Komputer, Universitas Teknokrat Indonesia \\ ${ }^{2}$ Jurusan Teknik Elektro Fakultas Teknik dan Ilmu Komputer, Universitas Teknokrat Indonesia \\ Jl. Zainal Abidin Pagar Alam No.9-11, Labuhan Ratu, Kedaton, Kota Bandar Lampung, Lampung 35132 \\ Email: ${ }^{1}$ kisamilirpengandonan@gmail.com, ${ }^{2}$ nando.tekno@gmail.com, ${ }^{3}$ sampoerna.go@teknokrat.ac.id
}

\begin{abstract}
Abstrak
Game detektif resimen mahasiswa batalyon 209 teknokrat gajah lampung merupakan sebuah game yang diangkat berdasarkan suatu unit kegiatan mahasiswa dengan tujuan untuk memperkenalkan resimen kedalam lingkungan yang lebih luas. Dengan mengetahui game detektif resimen mahasiswa batalyon 209 teknokrat gajah lampung maka pemain dapat menambah wawasan mengenai dampak dan bahaya pungutan liar dan resimen mahasiswa. Teknik pengumpulan data yang dilakukan pada penelitian ini yaitu menggunakan wawancara, tinjauan pustaka, dokumentasi dan kuisioner. Sumber data/subjek yaitu mahasiswa berjumlah 20 orang. Metode pengujian yang dilakukan yaitu aspek Fungsionality dan Usability. Aplikasi game detektif resimen mahasiswa batalyon 209 teknokrat gajah lampung menggunakan metode MDLC (Multimedia Development Life Cycle) tools yang dipakai yaitu Construct 2 yang dijalankan pada Android.Hasil pengujian ISO 9126 kualitas aplikasi game detektif resimen mahasiswa batalyon 209 teknokrat gajah lampung diperoleh nilai dari aspek fungsionality dan usability, dengan variable yang dinilai berupa kriteria Understandability 85\%, Learnability 85\%, Operability 87\%, dan Attractiveness $88 \%$. Untuk persentase secara keseluruhan dari aspek fungsionality dan usability hasil dari pengolahan data pada uji fungsionality dan usability menyatakan bahwa dalam penyebaran datanya sudah berdistribusi secara normal dan Game detektif resimen mahasiswa batalyon 209 teknokrat gajah lampung dapat dijadikan sebagai game dari pernyataan kuisioner yang telah diisi.
\end{abstract}

Kata Kunci: android, construct 2, game detektif, MDLC, ISO 9126.

\section{Pendahuluan}

Game adalah permainan yang dibuat dengan tujuan pembelajaran yang bukan hanya bermaksud menghibur tetapi juga diharapkan bisa menambah wawasan pengetahuan (Desta, 2016). Berdasarkan type nya Game bisa terdiri dari beberapa genre game yang masing masing memiliki karakteristik tersendiri, yakni: genre action games, strategy games, role playing games, sport games, vehicle simulations, construction and management simulations, adventure games, serta artificial life, board and puzzle (Martono, 2015: 23-30).
Salah satunya Game Detektif Resimen Mahasiswa Batalyon 209 Teknokrat Gajah Lampung Menggunakan Counstruct 2.

Resimen Mahasiswa (MENWA) merupakan salah satu komponen warga negara yang mendapat pelatihan militer (unsur mahasiswa). Kegiatan Resimen Mahasiswa bertujuan mempersiapkan anggota Resimen Mahasiswa yang memiliki sikap disiplin pengetahuan, fisik dan mental agar mampu melaksanakan tugas Bela Negara serta menanamkan dasar - dasar kepemimpinan dengan tetap mengacu pada kepentingan nasional. kegiatan ini bersifat non-formal (ekstrakurikuler) dalam bentuk Unit Kegiatan Mahasiswa (UKM) Perguruan Tinggi. Peran Resimen Mahasiswa dalam menumbuhkan kesadaran Bela Negara tertuang pada Panca Dharma Satya Resimen Mahasiswa Indonesia yang terdiri dari 5 nilai moral dan merupakan materi wajib yang diberikan pada tahun pertama hingga tingkat Sarjana Muda.

Berdasarkan latar belakang tersebut, penulis ingin merancang sebuah game android berlatar belakang Resimen Mahasiswa (MENWA) dengan tema Pungutan Liar. Pungutan liar merupakan suatu kejahatan yang patut diperhitungkan sebagai perbuatan yang sangat merugikan. Hal ini tidak boleh dibiarkan terus berlanjut tanpa adanya suatu penyelesaian hukum atas tindak pidanan tersebut. Oleh karenanya, setiap tindak pidana yang dilakukan oleh siapapun harus ditindak secara tegas tanpa memandang status dan jabatan pelakunya.

Dalam pengembangannya nanti game bergenre casual, dimana nantinya pada alur cerita game ini menceritakan tentang seorang Resimen Mahasiswa yang berperan sebagai detektif yang di tugaskan untuk mengungkap sebuah kasus. Kasus yang akan di pecahkan dalam game ini seperti kasus pungli yang terdapat di tempat- tempat strategis di provinsi lampung. Detektif Resimen Mahasiswa akan melakukan olah tkp, identifikasi kejahatan hingga menemukan petunjuk dalam pencarian barang bukti, setelah menemukan barang bukti maka akan di minta untuk menganalisis barang bukti tersebut. Dalam melakukan penyelesaian kassus detektif Resimen Mahasiswa akan dibuat dengan konsep petualangan dan puzzle didalam game tersebut. Dimana nantinya pengguna atau pemain harus menyelesaikan sebuah permainan yang telah dibuat baik itu berupa petualangan ataupun puzzle yang ada disetiap level pada game. 


\section{Metode}

\subsection{Kerangka Penelitian}

Kerangka pemikiran merupakan bentuk dari keseluruan proses dalam penelitian, diawali dengan identifikasi masalah, kemudian usulan solusi, dilanjutkan ke tahap pengembangan, mendapatkan hasil pembahasan dan kesimpulan. Adapun kerangka pemikiran dari penelitian ini dapat dilihat pada Gambar 2.

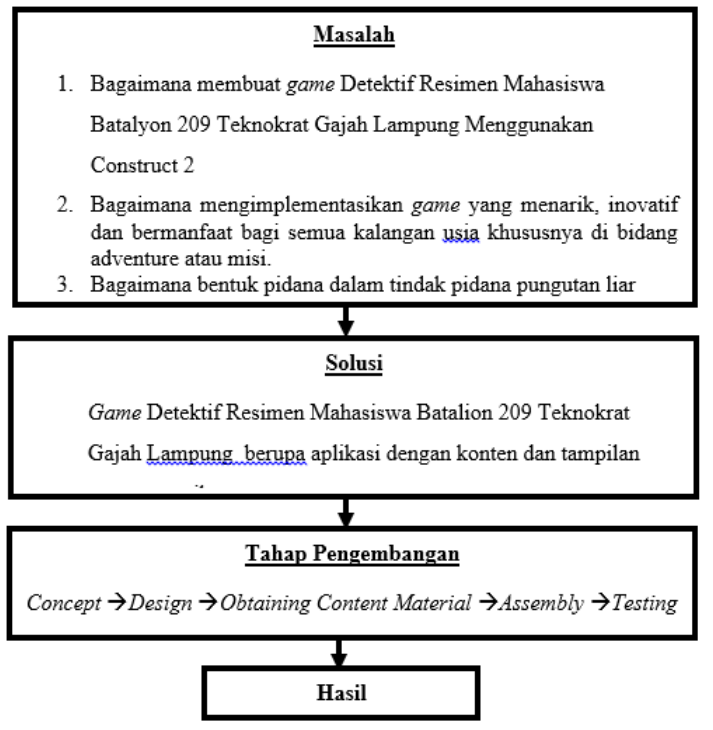

Gambar 2. Kerangka Penelitian

\subsection{Tahapan Penelitian}

Tahapan penelitian untuk membangun Game Detektif Resimen Mahasiswa Batalyon 209 Teknokrat Gajah Lampung Menggunakan Construct 2 adalah sebagai berikut:

a. Studi Literatur

Pada tahap ini dilakukan untuk mengkaji literatur baik berupa jurnal dan skripsi dengan cara mempelajari berbagai laporan-laporan ilmiah dan dokumen atau sumber bacaan serta buku-buku yang berkaitan atau berhubungan dengan topik penelitian.

b. Pengumpulan Data

Pada tahap ini dilakukan pengumpulan data oleh peneliti dengan cara study kasus di kemenkumham hal itu dilakukan dengan maksud untuk mendapatkan data dan informasi secara langsung yang benar-benar terjadi.

c. Design dan Implementasi

Tahap ini dilakukan untuk desain aplikasi yang dapat mempermudah dalam melakukan penelitian sehingga gambaran game yang akan dibuat jelas maksud dan tujuannya.

d. Pengujian Aplikasi Menggunakan ISO 9126

Pada tahap ini penulis melakukan pengujian kelayakan terhadap pembuatan Game Detektif Resimen Mahasiswa Batalyon 209 Teknokrat Gajah Lampung Menggunakan Construct 2.

e. Hasil

Game Detektif Resimen Mahasiswa Batalyon 209 Teknokrat Gajah Lampung Menggunakan Construct 2 .

\subsection{Struktur Navigasi}

Struktur navigasi merupakan hubungan antar menu. Struktur navigasi juga dapat mempermudah dalam mendeskripsikan rancangan navigasi pada game ini. Struktur navigasi pada game ini menggunakan model hierarchical. Adapun gambaran struktur navigasi dapat dilihat pada Gambar 3.

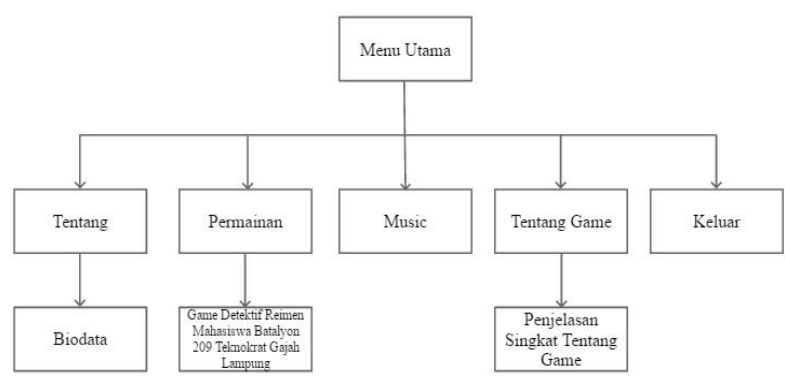

Gambar 3. Struktur Navigasi

\subsection{Flowchart}

Dalam aplikasi game ini flowchart diagram digunakan untuk menggambarkan alur program. Flowchart diagram dapat dilihat pada Gambar 4.

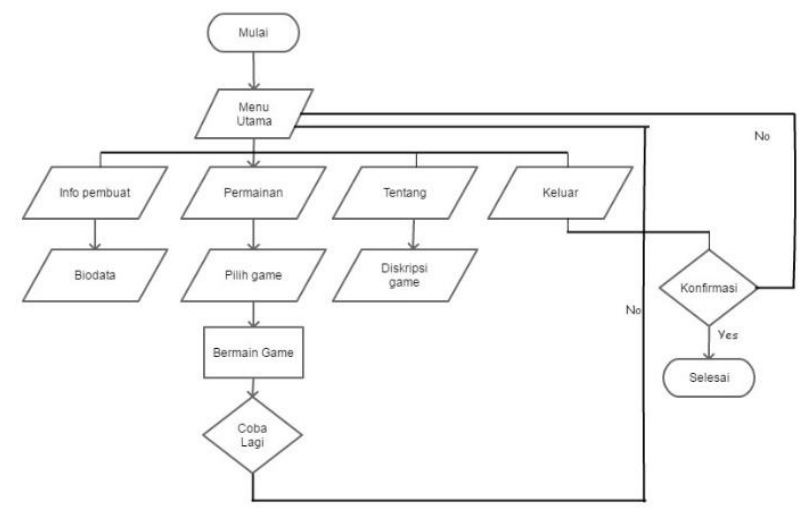

Gambar 4. Flowchart

\subsection{Pengujian}

Skenario pengujian game yang dibuat nantinya akan menggunakan standar kualitas ISO 9126.

\section{Hasil dan Pembahasan}

Tahap implementasi merupakan tahap translasi yang telah dirancang ke dalam program. Implementasi yang dilakukan sesuai dengan storyboard yang sudah dibuat, berikut hasil implementasi rancangan interface.

1. Loading Screen

Halaman loading screen adalah tampilan pertama kali ketika game dijalankan, halaman loading screen berisikan logo aplikasi Construct 2. Hasil implementasi loading screen dapat dilihat pada Gambar 5. 


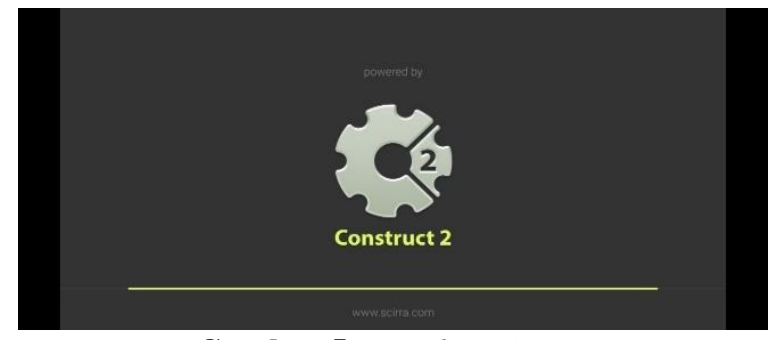

Gambar 5. Loading Screen

\section{Menu Utama}

Pada menu utama game terdapat beberapa tombol mulai dari tombol sound yang berfungsi untuk mengatur music pada game, tombol exit yang berfungsi untuk keluar dari game atau berhenti bermain, tombol petunjuk yang berfungsi untuk menunjukkan atau tata cara dari permainan sebuah game. Tombol mulai yang berfungsi untuk memulai game dan dapat melanjutkan ke menu pilihan game. Berikut tampilan implementasi menu utama yang dapat dilihat pada Gambar 6.

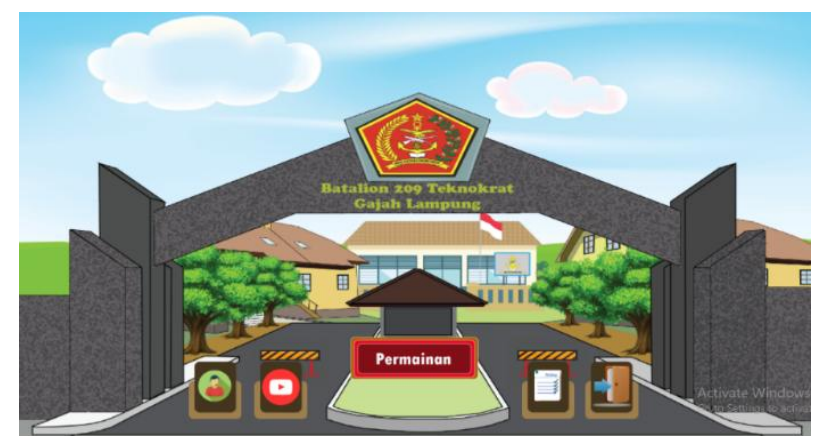

Gambar 6. Menu Utama

3. Tampilan Level 1

Halaman tampilan Level game berisikan permainan yang berkaitan dengan pungutan liar yang berada di sekitaran taman kota yaitu tentang pungli tanpa kekerasan atau tanpa ancaman dan tidak membahayakan keselamatan seseorang. Dimana permainan ini akan diberikan waktu selama 20 detik untuk dapat mencari barang bukti yang di masukan dalam arena permainan. Hasil implementasi tampilan game pencarian barang bukti dapat dilihat pada Gambar 7.

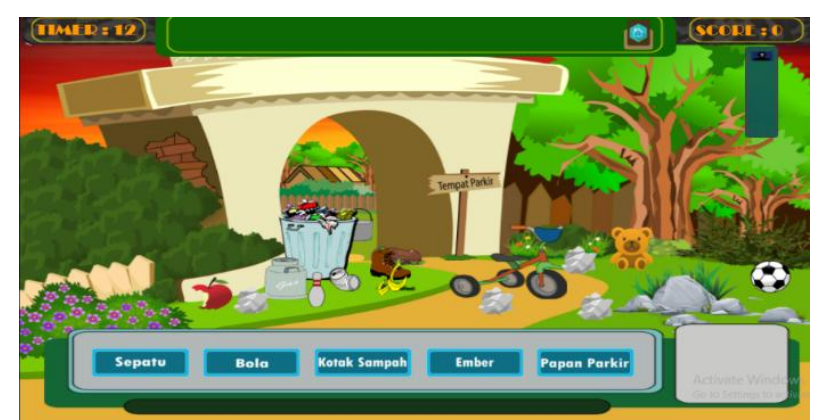

Gambar 7. Tampilan Level 1

4. Tampilan Menu Identifikasi

Setelah berhasil mengumpulkan barang bukti maka akan di masuk ke Halaman tampilan permainan
Identifikasi untuk memeriksa barang bukti yang di temukan dari game yang telah dimainkan. Selanjutnya user juga dapat memilih untuk melanjutkan game berikutnya, untuk memeriksa barang bukti dalam permainan. Hasil implementasi tampilan Identifikasi Barang Bukti Gambar 8.

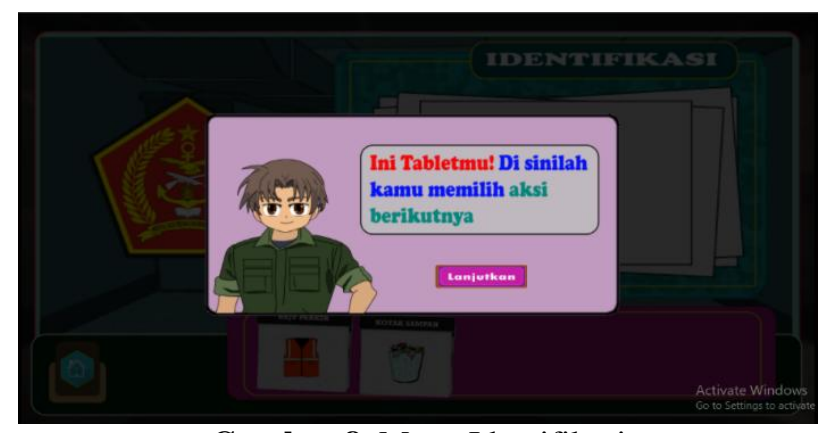

Gambar 8. Menu Identifikasi

\section{Tampilan Tangkap Pelaku}

Setelah berhasil memeriksa baran bukti maka akan masuk ke halaman tampilan tangkap pelaku. Selanjutnya user juga dapat mencocok kan barang bukti yang telah di temukan dalam tempat kejadian perkara setelah barang bukti di cocok kan dan terbukti bersalah maka user dapat menangkap pelakunya. Selanjutnya user dapat melanjutkan ke halaman level permaianan berikutnya untuk melanjutkan permainan. Hasil implementasi tampilan Tangkap Pelaku pada Gambar 9.

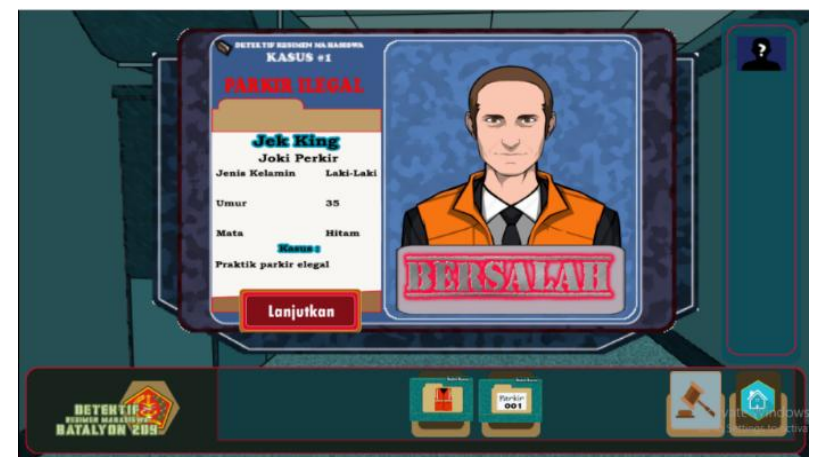

Gambar 9. Menu Tangkap Pelaku

6. Tampilan Permainan Complete

Halaman tampilan permainan Complete dari game Detektif Resimen Mahasiswa, maka tampillah Pengetahuan singkat dari Pungutan Liar dan Resimen Mahasiswa sebagai hadiah dari game yang telah dimainkan. Selanjutnya User juga dapat memilih untuk melanjutkan game berikutnya, mengulang permainan, dan kembali ke menu utama. Hasil implementasi tampilan Game Complete Detektif Resimen Mahasiswa pada Gambar 10. 


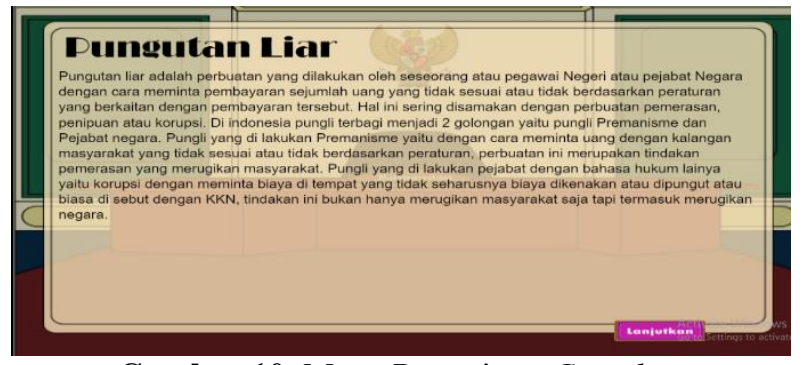

Gambar 10. Menu Permainan Complete

7. Tampilan pilihan level game

Halaman menu pilihan level game berisikan pilihan Level game selanjutnya dari Detektif Resimen Mahasiswa. Mulai dari level game 1 sampai dengan level game 5. Hasil implementasi menu pilihan level game dapat dilihat pada Gambar 11.

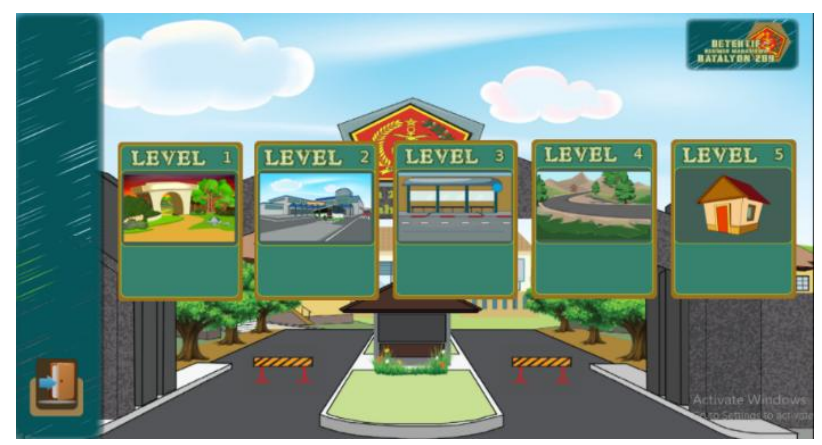

Gambar 11. Menu Level Game

8. Tampilan Menu Pembuat

Tampilan halaman tentang game berisikan informasi tentang pembuat game, dan judul game. Hasil implementasi tampilan tentang game dapat dilihat pada Gambar 12.

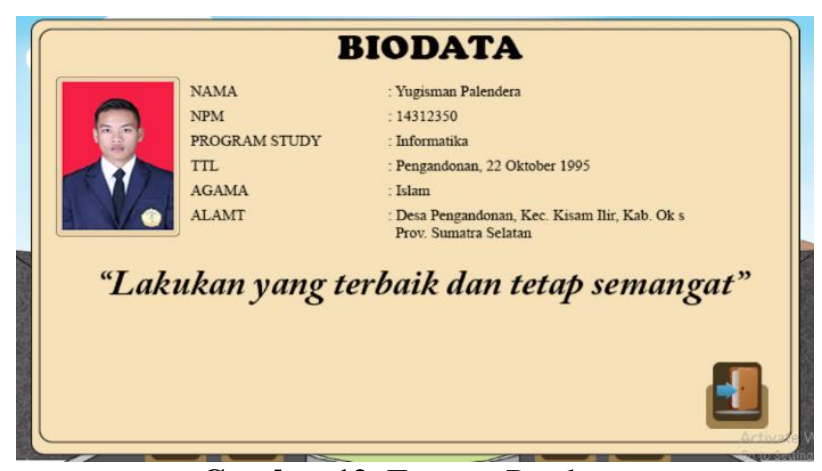

Gambar 12. Tentang Pembuat

9. Tampilan Game Over

Halaman tampilan permainan gagal dari game akan muncul ketika user gagal menyelesaikan pada game, user dapat mengulang permainan atau kembali. Hasil

[3] Rahadi, R. M., Kodrat, I. S. \& Ike, P. I., 2016. Perancangan Game Math Advanture Sebagai Media Pembelajaran Matematika Berbasis Android. Teknologi dan Sistem Komputer, Volume 4, No 1 Januari 2016.

[4] Siti, F., Fera, A. \& dan Elis, H., 2017. Role Playing Game SKU Pramuka Penggalang. Procedding, Volume .3, No 1. implementasi tampilan tampilan game pada saat gagal dapat dilihat pada Gambar 13.

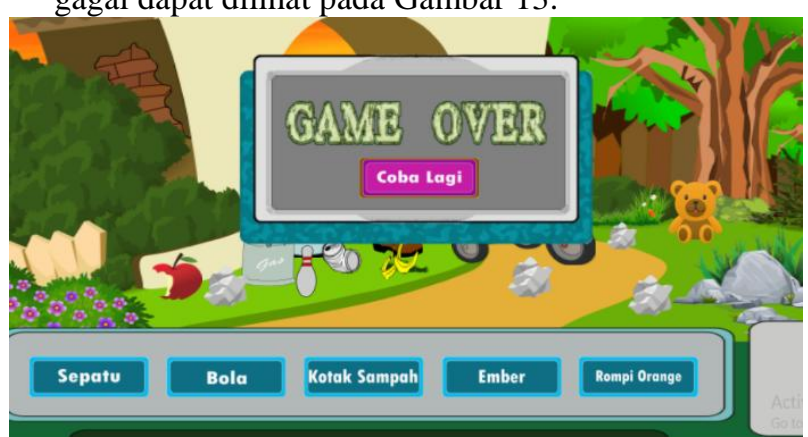

Gambar 13. Menu Game Over

\section{Kesimpulan}

Telah dibangun game Detektif Resimen Mahasiswa Batalyon 209 Teknokat Gajah Lampung Menggunakan Construct 2, menggunakan metode MDLC (Multimedia Development Life Cycle) dengan menggunakan construct 2 yang di implementasikan di Android.

Hasil pengujian ISO 9126 dengan variable fungsionality dan usability dalam penyebaran data kuisionernya berjumlah 20 responden, dengan variable yang dinilai berupa kriteria Understandability 85\%, Learnability 85\%, Operability $87 \%$, dan Attractiveness $88 \%$. Untuk persentase secara keseluruhan dari aspek fungsionality dan usability tentang game Detektif Resimen Mahasiswa Batalyon 209 Teknokat Gajah Lampung Menggunakan Construct 2 di peroleh dengan nilai $100 \%$ Fungsionality dan $87 \%$ Usability.

Adapun saran yang diberikan yaitu, game dapat dikembangkan dengan menambahkan misi dan tantangan pada game, kasus-kasus baru yang akan di pecahkan pada game berikutnya. Pengembangan algoritma khusus lagi dalam permainan fuzzel agar dapat lebih menarik tantangan pada permainan.

\section{Daftar Pustaka}

[1] Arisinta, R., Bayu, H. W. \& Ima, W. P. U., 2017. Pengembangan Group Investigation Dengan Permainan Aku Seorang Detektif Kelas Iv $\mathrm{Sd}$ Muhammadiyah 1 Malang. Jurnal Pemikiran dan Pengembangan SD, Volume 5, Nomor 2, September 2017, pp. 732-742.

[2] Purwaningsih, A. I. \& Sofyan, A. F., 2011. Pembuatan Game House Petualangan Harta Tersembunyi Menggunakan Adobe Flash. Jurnal Dasi, Volume 12 No.3 September 2011.

[5] Lubis, R. J. I., 2015. Peranan Resimen Mahasiswa Universitas Lampungdalam Membina Kesadaran Bela Negara Di Batalyon 201 Pemukul. Skripsi Unila, pp. 1-18.

[6] Nazarudin, S. H., 2012. Pemerograman Aplikasi Mobile Smartphone Dan Tablet PC Berbasis Android. Bandung Informatika.

[7] Rustiyanto, H. K., 2014. Upaya Polisi Dalam 
Menanggulangi Pungutan Liar Terhadap Supir Truk Galian Di Wilayah Kabupaten Sleman. Naskah Akademik, pp. 1 - 17.

[8] Sulawesi, B. P., 2016. Pungutan Liar Dalam Perspektif Tindak Pidana Korupsi. Edisi Triwulan III, Volume 26, pp. 1-36.

[9] John , W. \& S., 2014. Gaming Development Fundamentals. s.1.:Microsoft Official Academic Course.

[10] Nazruddin, S. H., 2012. Pemrograman Aplikasi Mobile Smartphone Dan Table PC Berbasis Android. Bandung: Informatika.
[11] Prayoga, S. H. \& Sensuse, D. I., 2010. Analisis Usability Pada Aplikasi Berbasis Web dengan Mengadopsi Model Kepuasan Pengguna (user Satisfaction). Jurnal Sistem Informasi MTI-UI, Jakarta.

[12] Rozi, F. Z., 2010. Pengertian game atau permainan, s.1.:http://erepo.unud.ac.id/9514/3/84e889030807459 8fcf70278cff785ee.pdf, diakses pada tanggal 15/05/2018. Pukul 17.00.

[13] Tian, J., 2005. Software quality engineering: testing, quality assurance, and quantifiable improvement. John Wiley \& Sons. s.1.:s.n. 